University of Louisville

ThinkIR: The University of Louisville's Institutional Repository

Electronic Theses and Dissertations

$12-2020$

\title{
External homophobia and outness in gay men.
}

Thomas Charles Isaak Jr

University of Louisville

Follow this and additional works at: https://ir.library.louisville.edu/etd

Part of the Gender and Sexuality Commons

\section{Recommended Citation}

Isaak, Thomas Charles Jr, "External homophobia and outness in gay men." (2020). Electronic Theses and Dissertations. Paper 3564.

https://doi.org/10.18297/etd/3564

This Master's Thesis is brought to you for free and open access by ThinkIR: The University of Louisville's Institutional Repository. It has been accepted for inclusion in Electronic Theses and Dissertations by an authorized administrator of ThinkIR: The University of Louisville's Institutional Repository. This title appears here courtesy of the author, who has retained all other copyrights. For more information, please contact thinkir@louisville.edu. 
EXTERNAL HOMOPHOBIA AND OUTNESS IN GAY MEN

\author{
By \\ Thomas Charles Isaak Jr \\ B.S., Murray State University, 2013 \\ M.A., University of Louisville, 2020 \\ A Thesis \\ submitted to the Faculty of the \\ College of Arts and Science of the University of Louisville \\ in Partial Fulfillment of the Requirements \\ for the Degree of \\ Master of Arts \\ In Sociology \\ Department of Sociology \\ University of Louisville \\ Louisville, Kentucky
}

December 2020 



\section{EXTERNAL HOMOPHOBIA AND OUTNESS IN GAY MEN}

By

Thomas Charles Isaak Jr

B.S., Murray State University, 2013

A Thesis Approved on

September 23, 2020

By the following Thesis Committee:

Dr. Latricia Best, $\mathrm{PhD}$

Dr. Karen Christopher, PhD

Dr. Kalia Story, PhD 


\section{DEDICATION}

This thesis is dedicated to my parents Theresa Ann Isaak and Thomas Charles Isaak Sr.

Though you may not be here to see this, I will forever carry the lessons of perseverance,

forgiveness, and love that you instilled in me over the years. May you both rest in peace. 


\section{ACKNOWLEDGEMENTS}

I would like to thank my thesis chair, Dr. Latricia Best, for her patience and guidance across this journey and for continuously encouraging me to dig deeper. I would also like to thank the other committee members, Dr. Karen Christopher and Dr. Kalia Story, for their guidance and patience over the past year. I would also like to thank my partner, Mike, for his relentless support. Thank you for never giving up on me and know that I appreciate the many sacrifices you have made over the years. I would also like to thank my sisters Rachel and Mary for their continued encouragement and for always listening to me when I needed them. 


\section{ABSTRACT \\ EXTERNAL HOMOPHOBIA AND OUTNESS AMONG GAY MEN \\ Thomas Charles Isaak Jr}

September 23, 2020

Prior studies regarding outness among gay men have often focused on internalized homophobia as a barrier to coming out for gay men, while less emphasis has been placed on external homophobia. Drawing upon social construction theory and Connell's hierarchy of masculinity, I utilize data from the 2010 Social Justice Sexuality Project to complete an ordinary least square regression to examine the impact of external homophobia on the level of outness among the 987 gay men in this study. In this study, I find that gay men who were exposed to external homophobia reported decreased levels of outness. Further, I find race impacted the level of outness among the gay men. Drawing from prior research on race, masculinity, and sexuality, I suggest that men with intersecting identities are not only held accountable to the White, heteronormative definition of hegemonic masculinity, but to other non-hegemonic forms of masculinity as well. 


\section{TABLE OF CONTENTS}

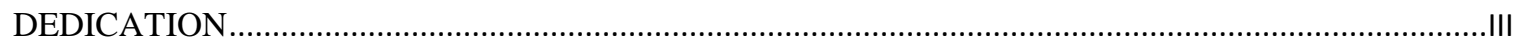

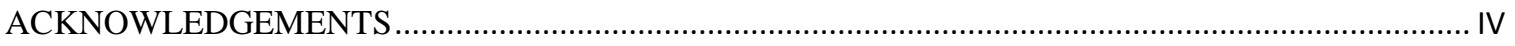

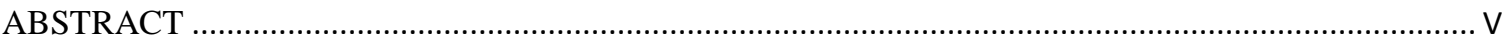

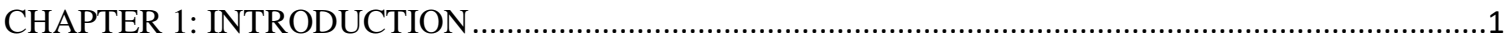

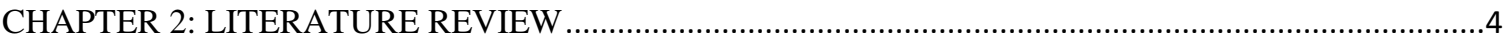

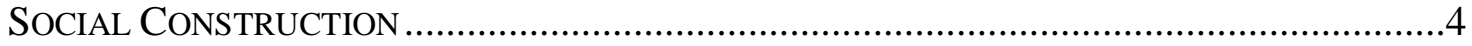

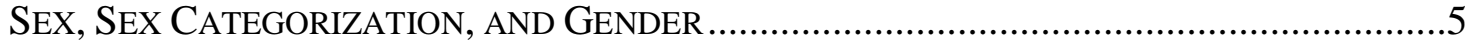

HEGEMONIC MASCULINITY, ACCOUNTABILITY, AND HIERARCHY .................................. 7

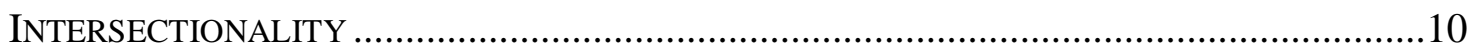

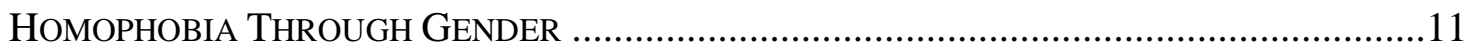

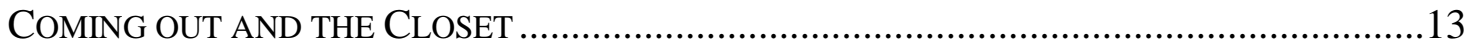

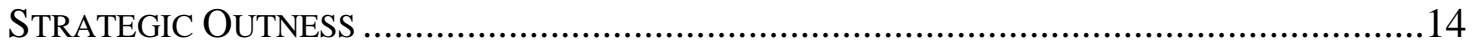

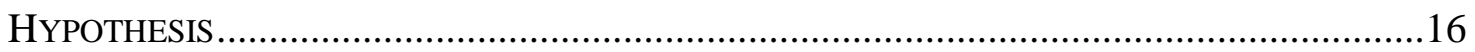

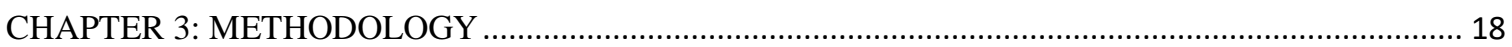

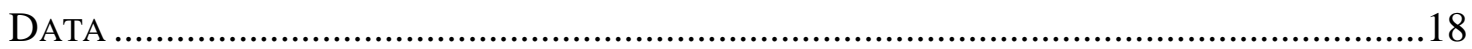

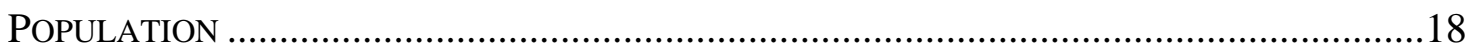

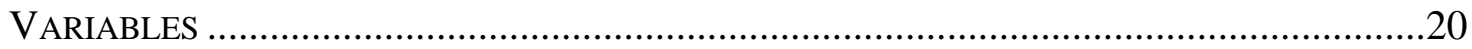

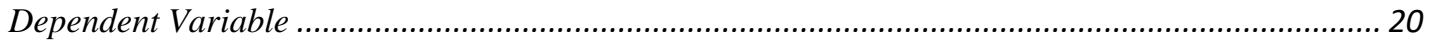

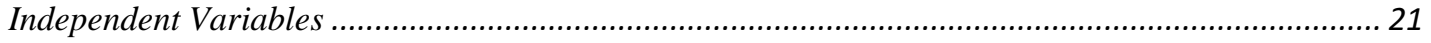

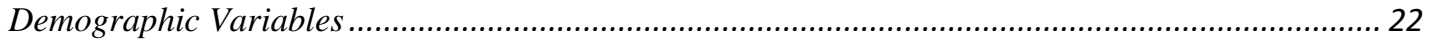

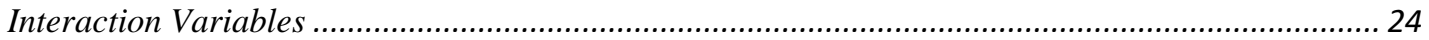

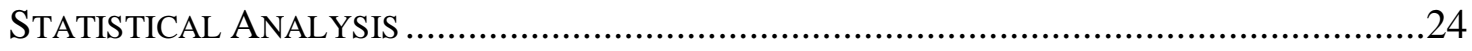

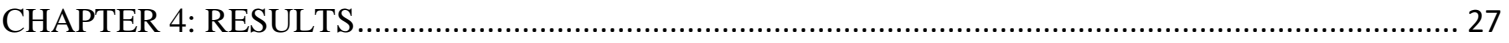

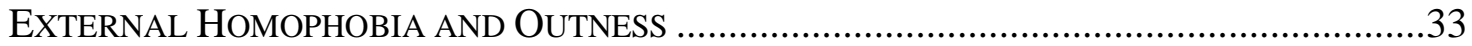

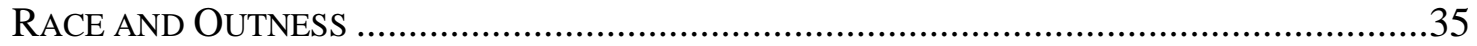

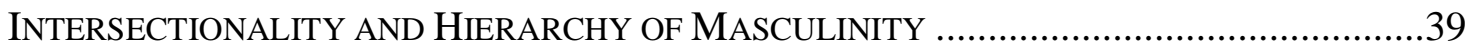

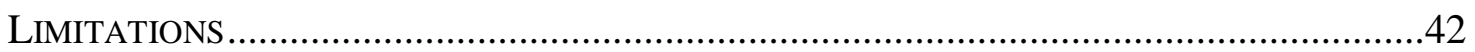

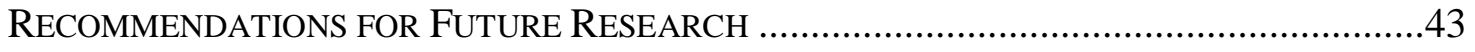

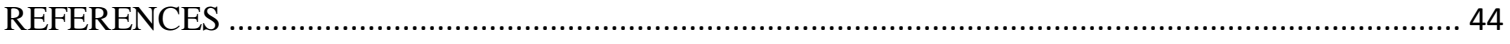

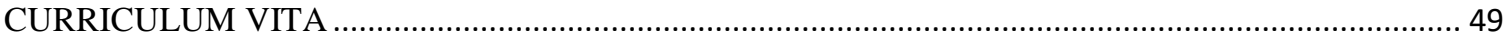




\section{CHAPTER 1: INTRODUCTION}

In the United States, acceptance of gay identities has grown over the past few decades (Pew Research Center 2017). This growth in acceptance of gay identities has helped gay men be able to come out regarding their sexual orientation. That is, gay men have been able to use various methods to inform others regarding their sexual orientation (Orne 2011). The growing acceptance, coupled with an increase in gay men coming out as gay, has led some scholars to believe that we have moved into a 'post-gay' society, where gay identities are now normal, routine, and unremarkable (Orne 2011). However, viewing society as post-gay fails to recognize that, regardless of the acceptance of gay identities, gay men remain positioned lower in the stratified social hierarchy and continue to face risks associated with coming out.

For gay men, there are multiple risks associated with coming out. One risk gay men face is the stratified social hierarchy in which they are placed lower than straight men. Stratification refers to "the unequal distribution of people across social categories that are characterized by differential access to scarce resources," in which gay men face less prestige (Bhana and Mayeza 2016), less upward mobility in jobs (Aksoy, Carpenter, Frank et al. 2018), and are less safe as they are considered easy targets for violence (Bhana and Mayeza 2016, Franklin 1998). Through their position in the stratified social hierarchy, society views gay men as lesser men, and gay men face homophobia. When examining the interaction between heterosexual psychoanalysts and non-heterosexuals, 
George Weinberg noticed that many psychoanalysts displayed strong adverse reactions. Weinberg identified this adverse reaction as homophobia: "a fear of homosexuals which seemed to be associated with a fear of contagion, a fear of reducing the things one fought for...(Herek 2004)." Though homophobia may include many actions, homophobia is often in the form of rejection, discrimination, and violence towards gay men (Herek 2004). While homophobia may be internal or external, internalized homophobia has been the main focus of scholars, as they focus on the psychological aspect of coming out (Orne 2011). Through internalized homophobia, gay men reflect the negative myths and stereotypes about gay identities inward and believe that they are true (Herek 2004). Literature regarding external homophobia and its effects on coming out for gay men are lacking. External homophobia refers to "overtly observed or experienced expression of internal biases such as social avoidance, verbal abuse, and civil discrimination (Banks 2003)." This research focuses on external homophobia, as external homophobia allows for a better understanding of the dynamics between straight men and gay men in society.

This research project seeks to answer, "How does external homophobia affect gay men's level of outness?" To answer this, I begin with a review of the relevant literature regarding sex, sex categorization, and gender. These topics are intertwined with sexuality (Herek 2004, Kite and Whitley 1998), and past studies have confirmed the role that they play in understanding why gay men are subjected to homophobia (Bhana and Mayeza 2016, Franklin 1998). This project is informed by Connell's hierarchy of masculinities through which we understand the social hierarchy as it relates to gender and sexuality. This project is further informed by intersectionality, which is addressed throughout the entire project. From this point, I move to a discussion of outness, outlining what it means 
to be out and motivations for coming out. I close the literature review with a review of the methods gay men use to come out and a discussion of Goffman's (1959) dramaturgical loyalty to discuss how homophobia influences the way that gay men come out. I then use a quantitative approach to discuss how external homophobia affects gay men's level of outness. To do so, I use data from the Social Justice Sexuality Project from 2010 (Juan Battle, Pastrana Jr and Daniels 2013). This dataset is incredibly valuable, as the project focused on collecting data from a racially diverse population, with respondents including Asian and Pacific Islander, Black, Latinx, White, and Multiracial identities from across all 50 states, Washington, D.C., and Puerto Rico. As such, the data allows for insight into experiences across the gay community versus the current narrative, which marginalizes the experience of gay men of color. 


\section{CHAPTER 2: LITERATURE REVIEW}

\section{Social Construction}

According to social construction theory, reality is socially constructed through shared meanings given to people and interactions (Berger and Luckmann 1966). That is, individuals share meanings that collectively become commonsense knowledge (Berger and Luckmann 1966). As individuals interact with one another, interactions become habitualized. That is, the interaction is performed in the same way when performed again (Berger and Luckmann 1966). As these interactions become habitualized, individuals in society begin to develop typification schemes. People then use these typification schemes to categorize others based on the characteristics believed to represent that category" (Berger and Luckmann 1966). These interactions become institutionalized as individuals of different typifications "agree" that individuals of $\mathrm{X}$ typification will do $\mathrm{X}$ action. These typifications become part of the social stock of knowledge, which is passed down by parents, caregivers, and other socializing agents through socialization. Socialization is both an externalization and internalization of an ongoing dialectical process. That is, parents/ caretakers/ socializing personnel externalize reality when they socialize their other individuals, as they have now projected their reality into the world by solidifying their objectivation of their routines (Berger and Luckmann 1967:58-59). The parent/ caregiver teaching their child crystallizes the social world to the child in a way that the child assumes these socialized norms are part of the given reality (Berger and Luckmann 
1967:59). However, only pieces of this information are retained and are "congeal in recollection as recognizable and memorable entities" (Berger and Luckmann 1966). Once typifications have been formed, socialized to the next generation and sedimented, as time passes historicity is established, and the interaction is considered an institution.

In examining the process of constructing reality, it is crucial to understand that institutions play a role. Institutions such as religion, politics, and medicine have been critical to the construction of sexuality. In constructing sexuality, religion has constructed sexuality through the position of power religion holds in many institutions. For example, the right-wing of the Republican Party and the Christian Right Movement, LGBTQ+ individuals have had difficulty achieving the Gay Liberation Movement's goals. Religion's ties with the state create an environment through which it is often difficult or impossible to get queer-friendly legislation passed due to moral opposition (Seidman 2010).

Sex, Sex Categorization, and Gender

As many institutions have pushed for a heterosexist focus on sexuality, they have required a well-defined difference between sexes. This differentiation between sexes has, for the most part, been provided by the medical/ scientific community, through the identification of sex chromosomes. However, in western societies, gender is viewed as being derived from the individual's sex (West and Zimmerman 1987). However, gender is the managing of conduct according to what is socially acceptable for someone's assumed sex (West and Zimmerman 1987, West and Fenstermaker 1995). Thus, these terms are different, and the differences between the two terms help understand how society views individuals. 
In understanding sex, society uses biological criteria present at birth to determine if someone is male or female. However, the criteria for determining a person's sex is not always readily available, and as such, society places individuals in a sex category that aligns with their display (West and Zimmerman 1987, West and Fenstermaker 1995). The process in which society assumes someone's sex through their displays is called sex categorization. Sex categorization uses appearances and understands them as indicative of the biological criteria for sex. As such, it does not require the biological criteria to be met to be placed in a sex category (West and Zimmerman 1987, West and Fenstermaker 1995). Through the sex category, gender emerges and supports a person's claim to the sex categories (West and Zimmerman 1987).

Through sex and sex categorization, gender becomes something that is done. Gender is managing activities according to what is deemed socially acceptable according to the individual's sex categorization. Through this, gender is an accomplishment of social interactions and not merely the traits associated with a sex categorization (West and Zimmerman 1987). However, western society views sex dichotomously (West and Fenstermaker 1995), and that a person's gender derives from their sex (Page and Peacock 2013, West and Zimmerman 1987). As such, gender also becomes understood dichotomously, and the expectation is that those who are categorized as men will perform in a way that is deemed masculine. While it is typically true that sex and gender align in such a way (Page and Peacock 2013), when these do not align, society holds the individual accountable with subsequent consequences (West and Zimmerman 1987, West and Fenstermaker 1995). 
Hegemonic Masculinity, Accountability, and Hierarchy

In discussing gender as being done in interactions between individuals, the relationship both between genders and within genders is understood. As society determines what acts are appropriate displays for a sex category, they also hold those individuals accountable for their gender performance. According to John Heritage, accountability occurs as members of society routinely characterize activities and then place them in a social framework. In doing so, individuals are held accountable to their performance as men or women, and thus other activities are validated or discredited (West and Zimmerman 1987, West and Fenstermaker 1995). If society views a person as male or female, they understand their other activities in light of this and deem subsequent interactions appropriate if they adhere to that sex category's understood norms. Particularly for men, these activities are compared to the concept of hegemonic masculinity, and men are subsequently understood concerning how they perform according to hegemonic masculinity (Connell and Messerschmidt 2005).

Hegemony was initially used by Gramsci in 1971 to understand how a dominant class legitimized its rule in societies characterized by class inequality. Gramsci discussed that the ruling class sustains domination through the production of consent to its moral and intellectual leadership, rather than force or coercion (Jefferson 2002). That is, the ruling class must make their domination seem natural, a product of biology, and not a forced act (Donaldson 1993). Connell framed her studies of masculinity in this dynamic between dominant and subordinate groups and defined hegemonic masculinity as the patterns of practice that further continue men's domination over women and nonhegemonic forms of masculinity (Connell and Messerschmidt 2005). 
Hegemonic masculinity encompasses the most honored way of being a man. As such, all men are held accountable for their performance in accordance with hegemonic masculinity and are expected to position themselves according to the goals and norms of hegemonic masculinity (Connell and Messerschmidt 2005). In her examination of masculinity, Connell further identifies three relationships within masculinity to understand power relations in the gender hierarchy: complicity, marginalization, and subordination. While not all men embody hegemonic masculinity, some may continue to benefit from the existence of hegemonic masculinity. These men are not "simply a slacker version of hegemonic masculinity" but instead should be considered complicit (Connell 2005: 79). For some men, their race or class prevents them from achieving society's definition of hegemonic masculinity. These men are considered marginalized. This relationship between masculinities considers that gender is not experienced alone, but that other groups attempt to position themselves in relation to hegemonic masculinity may be unable to do so due to the relationship other identities. For example, while men of color can be considered an exemplar of hegemonic masculinity, the social authority of men of color is not affected by the few who are able to achieve such status (Jefferson 2002). The third relationship between masculinities Connell discusses is subordinated masculinity. This subordinated masculinity applies to men whose masculinity is easily related to femininity. For gay men, the subordination of their masculinity relies on stereotypes such as their taste in home décor and fashion, the belief that gay men are weak, and the act of same-sex intercourse (Bhana and Mayeza 2016, Connell 1995, Donaldson 1993). Through this understanding of gay men, society views gay men as lesser men, less capable compared to straight men, and deserving of fewer resources. 
In Connell's discussion of hegemonic, complicit, marginalized, and subordinate masculinities, she discusses that these forms of masculinity are not simply trait-based but based on relationships between those in power (hegemonic) and those who are not (Connell 1995).

By discussing the dynamic between groups, Connell creates a more in-depth understanding of the gender hierarchy by taking into account the multiple forms of masculinity in relation to femininity and hegemonic masculinity (Connell and Messerschmidt 2005). Gay men are understood in this gender hierarchy as being more closely identified to femininity through the stereotypes regarding gay men's interests and labeling these men as sissies and weak (Bhana and Mayeza 2016, Donaldson 1993). However, it is not only that they are seen as more feminine through these gendered stereotypes, but also that they are less masculine due to their failure to conform to the heteronormative bedrock of hegemonic masculinity (Donaldson 1993).

In hegemonic masculinity, gay men are understood as being lesser men due to heteronormativity. Through heteronormativity, heterosexuality is seen as the "natural and normative sexual orientation, thereby devaluing all other expressions of sexuality (Page and Peacock 2013)." In society, males and females are depicted as complimentary sexual partners, with women existing as sexual objects to provide sexual validation for men, while men are seen as in competition for women (Donaldson 1993, Page and Peacock 2013). This view of male and female roles in sexuality provides validation for the hierarchy in which men and women interact. However, in homosexuality, particularly for gay individuals, men become sexual objects to provide sexual validation and are competition, which threatens hegemonic masculinity's hierarchical nature (Donaldson 
1993). Furthermore, as heterosexual relationships view women as sex objects, gay men are associated with femininity as they are the sex object in gay relationships. As hegemonic masculinity requires that men position themselves to the idealized man (Connell and Messerschmidt 2005), taking on an understood female role leads to gay men being considered subordinate and, as such, placed below straight men in the stratified social hierarchy (Jefferson 2002). As gay men are placed in the stratified social hierarchy, they face homophobia, which maintains gender dichotomy (Franklin 1998).

Intersectionality

While gender and sex are intertwined, they also interact with numerous other identities, creating unique experiences of oppression and privilege among groups. That is, sex and gender are part of a large matrix of domination, which is "the overall organization of hierarchical power relations for any society, [which has] a particular arrangement of intersecting systems of oppression...[and] a particular organization of its domains of power" (Collins 2000: pg 229). This matrix of domination helps to examine the intersectional experiences of those with multiple identities such as race, sex, gender, and sexuality and how they overlap to create their unique experiences (Collins 2000, Crenshaw 1989).

Intersectionality has often been an issue in literature attempting to address the experiences of the queer community. Past literature of the queer community has often presented the experiences of White, cisgender gay men as the experience of all gay men (Hill 2009, Hunter 2010, Ocampo 2014). However, these previous studies marginalize the experience of gay men of color, as studies have shown that gay men of color experience higher levels of external homophobia (Chard, Finneran, Sullivan et al. 2015), policing of their adherence to heteronormative ideals (McCune Jr. 2014), and experience 
racism within the queer community (Ocampo 2012). By failing to address the intersections of race, gender, sex, and sexuality, the barriers that gay men of color face when coming out are marginalized, and thus the issues of those oppressed on intersecting identities are left unaddressed.

Homophobia Through Gender

The stratified social hierarchy is maintained by targeting and policing gay men's sexual orientation (Bhana and Mayeza 2016, McCune Jr. 2014). This policing of gay men's sexual orientation is often referred to as homophobia, which is often discussed as internalized homophobia or external homophobia. Research has primarily focused on internalized homophobia, the inward reflection of society's negative views regarding gay men (Herek 2004). However, through external homophobia, gay men are policed through actions such as violence, discrimination, and rejection (Franklin 1998, Herek 2004, McCune Jr. 2014). George Weinberg first used the term homophobia to understand these actions, defining homophobia as "a fear of homosexuals which seemed to be associated with a fear of contagion, a fear of reducing the things one fought for" (Herek 2004). Sociologist Michel Kimmel suggests that homophobia is not a fear of gay men, but is instead "man's fear of other men - that is, a man's fear that other men will expose him as insufficiently masculine (Herek 2004)." Here, it is possible to examine homophobia as a social issue, in that it becomes a product of the interaction between men, particularly between straight men and those who are perceived as being gay.

In male heterosexuality, hostility towards gay men is fundamental and helps straight men maintain their heterosexual identity (Donaldson 1993). In studies of youth, those who are labeled as gay are rejected and faced violence from peers who saw themselves as "real boys." The "real boys" identified gay boys as being feminine and, as 
such used violence towards gay boys and refused to allow them to play with them as a means of keeping themselves distanced from gay boys (Bhana and Mayeza 2016). Studies of gay assailants echo the gendered reasoning for violence (Franklin 1998). Karen Franklin's (1998) study of gay assailants found that assaults on gay men are a form of social control, meant to maintain gender norms. Men who fail to conform to these gender norms were labeled as feminine and weak and then bullied. Throughout this study, Franklin found that these norms' enforcement became a focal point for assailants, who used the violations to justify their actions. Franklin also found that peer dynamics played a role in these assaults. Through peer dynamics, the assaults became a way for these men to provide direct evidence of their masculinity to their peers. In this study, Franklin found that these assailants targeted gay men, as they were seen as easy targets to prove their strength and that gay men would not fight back. Franklin noted that women would be an easy target, but it would be cowardly to target women in their assaults. Also, as it is taboo for a man to hit a woman, the man may become instead listed as a coward instead of a cultural hero (Jefferson 2002). Though these studies support that the issue of homophobia is one that gay men face, the issue for gay men of color remains unique in several ways.

For gay men of color, there are multiple barriers to coming out. Gay men of color are often met with racism in the queer community and thus find less support in the process of coming out (Ocampo 2012). Black gay men are met with physical and verbal violence as a means of "policing their gender performance and sexual desire...teaching them what deemed them as proper Black men in the context of urban regimes of masculinity" (McCune Jr. 2014). However, Black gay men who do not come out are also 
villainized through media representations, which portray them as uncaring and selfish, while also blaming Black gay men for spreading sexually transmitted diseases to their girlfriend/ wife (McCune Jr. 2014). Latino gay men also face similar rejection issues, having been met with racism within the queer community and reporting high numbers of rejecting behaviors from parents/ caregivers (Haas, Eliason, Mays et al. 2011, Ocampo 2012). With these issues presenting barriers for gay men of color, they are often left with a difficult decision to come out as risk losing resources and social networks, or to remain closeted (Ocampo 2014).

Coming out and the Closet

Coming out can be a very emotional experience for gay individuals (Ocampo 2014), with this process being considered a milestone by many in the gay community. Coming out is defined as the process in which a person first acknowledges, accepts, and appreciates their sexual orientation or gender identity and begins to share that with others (Human Rights Campaign 2019)." However, coming out is problematic to the study of gay men, as it has multiple meanings for both researchers and gay men (Orne 2011). Coming out is often understood to be the opposite of closeted, where a gay individual has not disclosed their sexual orientation or gender identity (Human Rights Campaign 2019). Researchers have sought to define a clear path to the process of coming out, but have yet to find a model that has encompassed the experiences of intersecting identities (Hill 2009).

In studying gay men and outness, researchers have sought to define a clearly defined process for coming out. These models have provided useful insight into the development of a healthy gay identity, yet they have also largely been scrutinized (Hill 2009). Earlier models typically focused on disclosure as a sign that the person had 
accepted their identity. These models did not consider that disclosure may not be the gay man's goal, and that disclosure may not be safe for the gay man. Further, these models were scrutinized for their focus on white, middle-class gay men (Hill 2009, Hunter 2010, Ocampo 2014). Even when more recent models for outness were created and attempted to address the synthesis of gay identity with an individual's other identities, they still failed to capture the experiences of gay men of color, and thus were scrutinized for their focus on white, middle-class gay men (Hill 2009, Hunter 2010, Ocampo 2014). As such, these models failed to address the process of coming out for gay men of color, marginalizing the unique experiences, methods, and risks these men face.

Gay men seeking to come out or remain closeted may be motivated through their understanding of explosive knowledge and the concept of living a lie. Through explosive knowledge, gay men view their coming out as dangerous to both parties and remain closeted. However, gay men also may feel that to remain closeted is to live a lie, and as such, they may desire to come out (Orne 2011). Research has suggested that coming out provides benefits for gay men, yet there are many barriers to coming out. As gay men overcome these barriers, they often somewhere in between, not completely out, yet not completely closeted. To manage this, gay men may utilize various methods of coming out to ensure that they remain safe from the repercussions of explosive knowledge while balancing their outness.

\section{Strategic Outness}

As gay men decide to come out or remain closeted, they are motivated to do so in a way that mitigates the possibility of facing external homophobia. However, gay men often balance this risk associated with coming out with their desire to live in a way that they feel they are truthful to themselves. This balancing may lead to gay men coming out 
in some settings while remaining closeted in other settings. Thus, there are numerous methods of coming out that gay men may use, such as direct disclosure, clues, speculation, or concealment (Orne 2011).

Most literature regarding coming out has focused on direct disclosure as the method of coming out, in which the gay man directly states that he is gay out (Hill 2009, Orne 2011). However, gay men may also use clues by indirectly discussing their identity, such as mentioning what they have done in the community, but not directly stating that they are gay. Gay men may also allow for speculation, in which they do not give clues regarding their sexual orientation, nor do they deny it (Orne 2011). Speculation may be used because their gay identity is not their most salient of identity, or it may not be the most appropriate for the relationship they have with that person (Hunter 2010, Orne 2011).

While gay men may utilize these methods in coming out, they may completely conceal their sexual orientation to remain closeted. That is, they may change their behavior and manage their identity in a way that prevents others from knowing their sexual orientation (Orne 2011). While direct disclosure, clues, and speculation do not directly prohibit people from discovering the gay man's sexual orientation, concealment explicitly restricts others from knowing the gay man's sexual orientation (Orne 2011). Concealment may not be only directed at the individual whom a gay man does not want to know his sexual orientation, but also directed towards those that the gay man deems a threat to disclose this information without his consent (Orne 2011).

In The Presentation of Self in Everyday Life, Ervin Goffman (1959) examines social interactions, drawing a parallel to theatre performances. Goffman discusses that 
social interactions, much like theatre performances, are fragile and that poor performance can be disruptive (Ritzer and Stepnisky 2018). To prevent the performance from being disrupted, the actor must ensure that those participating in the performance possess the proper traits, which Goffman labels defensive attributes. If the performance is disrupted, actors are expected to employ these traits to save the show. These traits help ensure what the actor wants the audience to see is all that is seen. Gay men's concealment in relation to their outness can be viewed through what Goffman label's dramaturgical loyalty.

Gay men who wish to remain closeted with certain people may make sure that they do not tell people close to those they wish to remain closeted with (Orne 2011). This selective outness is because their secret regarding their gay identity may be disclosed in this setting. In Goffman's dramaturgical loyalty, actors choose other people they can ensure will not betray the performer's secret between performances for any reason (Goffman 1959). By ensuring that the other people that the actor is performing with possess this attribute, the actor may prevent a "faux pas" where the individual "unthinkingly makes an intentional contribution which destroys his own team's image (Goffman 1959)." Through this, gay men only tell people who will not tell their secret to whom they perform their straight identity. Gay men prevent the faux pas in this situation by keeping their groups separate to ensure that no information is accidentally told to the wrong person, as this could lead to the gay man experiencing external homophobia.

Hypothesis

While previous researchers have focused on the queer community and outness before, these researchers have often focused on the impact of internalized homophobia (Orne 2011). However, discussions of internalized homophobia do not capture the placement of gay men in the stratified social hierarchy. Therefore, for this study, my 
research question was, "How does external homophobia affect gay men's level of outness?" Based on prior literature, I hypothesize a statistically significant negative relationship between exposure to external homophobia and the level of outness reported by the gay men in this study. That is, I predict that as gay men are exposed to more external homophobia, their level of outness will decrease.

$\mathrm{H}_{1}$ : As gay men are exposed to more external homophobia, their level of outness will decrease.

$\mathrm{H}_{0}$ : As gay men are exposed to more external homophobia, their level of outness remains the same. 


\section{CHAPTER 3: METHODOLOGY}

Data

In this study, I use secondary data from the 2010 Social Justice Sexuality (SJS) survey. The SJS survey collected responses between January and December 2010 and focused on the experiences of Black, Latinx, Asian and Pacific Islander, and Multiracial lesbian, gay, bisexual, and transgender individuals. Responses were collected from all 50 states, Washington, D.C., and Puerto Rico. The SJS survey focused on "five themes: racial and sexual identity; spirituality and religion; mental and physical health; family formations and dynamics; civic and community engagement" (Battle 2010). Given concerns that past research in LGBTQ+ studies present the issues of White, cis-gender, gay men as representative of the LGBTQ+ community as a whole, this dataset is ideal as it provides a unique look at a highly diverse sample of the LGBTQ+ population.

\section{Population}

The SJS survey collected responses from 4,953 LGBTQ+ individuals via "venuebased sampling at strategic events, snowball sampling, respondent-driven sampling, and the internet" (Battle 2010). Given gay men who are not out to anyone would most likely not be at LGBT events, may not be known to other gay men, and may not be out on the internet, this sample is non-representative of the gay men in the United States. 
For this study, I only include cisgender gay men, leaving 1,593 cases.

Transgender gay men were not included in this sample, as the unique experiences of transphobia deserve more focus than this paper could give in the scope of studying homophobia. Further, this study did not include any other sexuality reported beyond gay, as there were forms of phobia related to those sexual identities that were also beyond the scope of this paper.

Next, respondents who had missing responses were removed from the analysis. When asked how out they were to the various communities, 20 gay men were missing their response to family, 20 gay men were missing their response to friends, 92 gay men were missing their response to their coworkers, 102 gay men were missing their response to their neighborhood, and 112 were missing their response to online. A review of the demographic variables in this study shows that 36 of the gay men were missing their response when asked their age, 21 of the gay men were missing their response when asked about their race, 73 of the gay men were missing their response when asked what religion they were currently practicing, 66 of the gay men were missing their response when asked about their political ideology, and 127 of the gay men were missing their response when they were asked where they lived. With regards to the homophobia questions, 14 of the gay men were missing their response to "homophobia is a problem within my racial or ethnic community," 18 of the gay men were missing their response to "homophobia is a problem in my neighborhood," 66 of the gay men were missing their response to "as a LGBT person, how much do you now feel supported by your family," and 28 of the gay men were missing their response to "thinking about the last medical 
professional you saw, do you feel that s/he." After the 544 cases that were missing responses were removed from this analysis, 1,049 cases remained in the study.

To examine the remaining 1,049 cases in this study, Cook's D was calculated to examine if any cases significantly influenced the OLS regression line created in the model. By examining these cases, unusual cases that may otherwise skew the results of the models were removed. As such, 62 of the gay men were removed due to their strong influence on the model as determined by Cook's D. Removing these 62 gay men from the analysis left a final sample of 987 gay men in this study.

Variables

Past literature examining barriers for gay men was examined to determine the appropriate variables for this study. Independent variables focused on homophobia in the respondent's community, interactions with medical professionals, rejection from family, and demographic variables such as age, political ideology, race, region, and religion. The relationship between these variables was examined against the respondents' level of outness.

Dependent Variable

This study used a composite variable for outness, measured by combining the responses of the matrix question "How many people within the following communities are you 'out' to?" This question was followed by six items: family, friends, religious community, coworkers, people in your neighborhood, and people online. Respondents were given a six-point ordinal scale ranging from $1=$ "none" to $5=$ "all" with an option for "not applicable." These variables were recoded for clarity, such that $0=$ "none" and $4=$ "all." The matrix item for outness to religious community had a high non-response rate among gay men (23.4\%). Therefore, this item was not used to create the dependent 
variable. Responses were combined to create a composite score for the respondent's overall level of outness, which resulted in a 21-point scale with $0=$ "out to none" and $20=$ "out to all." By combining these items into a larger scale, insight into the impact of external homophobia on gay men as a whole is better understood.

Independent Variables

In this study, independent variables focused on the experience of external homophobia. To examine the impact of homophobia in the gay men's communities, I created a composite variable by taking the mean response to "Homophobia is a problem in my racial and ethnic community" and "Homophobia is a problem in my neighborhood." Both variables were measured on a six-point Likert scale of $1=$ "strongly disagree" and $6=$ "strongly agree." By combining these variables, the score indicates the respondent's general feeling of homophobia as a problem. Particularly for gay men of color, the fear of losing socio-economic or social support may make them less inclined to come out. While White gay men may face the risk of losing support, they can typically maintain support from the LGBTQ+ community (Ocampo 2014). This variable is measured using an eleven-point ordinal scale of $1=$ "strongly disagree" and $6=$ "strongly agree."

To examine the impact of family rejection on the level of outness among the gay men in this sample, I recoded the question, "As a LGBT person, how much do you now feel supported by your family." Initially, this variable was a six-point Likert scale of $1=$ "not supported at all" and 6= "completely supported." To ensure the direction of this variable matched other variables in this study, I recoded the Likert scale so that $1=$ "completely supported" and $6=$ "not supported at all." By recoding this question, the experience of homophobia was found at higher points in the scale. Past research of LGB 
youth has shown that rejection by family members serves as a potent stressor (Haas et al. 2011), with youth being motivated to remain closeted for fear of losing socio-economic and social support if they are rejected by family members (Ocampo 2014). Respondents also had the option to respond, "they don't know I'm LGBT;" however, those who responded "they don't know I'm LGBT," were removed from the analysis, as this response was not gaging support, but instead indicates the level of outness to family members.

Regarding interactions with their medical professional, I created three dummy variables using the question, "Thinking about the last medical professional you saw, do you feel that s/he." Respondents were given the options of "seemed comfortable with your sexual identity," "seemed uncomfortable with your sexual identity," "seemed to ignore your sexual identity," and "did not know your sexual identity." Literature regarding LGBTQ+ healthcare has shown some physicians are not comfortable with homosexuality, and this permeates into their interactions with LGBTQ+ patients, leading some to consider the need to hide their sexual identity to assure they are treated with respect in the medical setting (Houghton 2018, Klitzman and Greenberg 2002). For this, I created three dummy variables: "comfortable," "uncomfortable/ ignored," and the reference group "did not know."

Demographic Variables

To understand the impact of religion on outness among the gay men in this study, I included the variable "In what religious tradition do you currently practice." This item was a particularly important concept to examine in this study, given the role of religion in constructing sexuality, particularly the heteronormative construction of sexuality (Seidman 2010). Though some religions accept gay individuals, this has been a relatively 
recent development in the span of the church. While these religions may be more accepting of gay individuals, many do so from a standpoint of "hate the sin, love the sinner." This ideology still alienates gay men, as it identifies their gay identity as something that is "wrong" and a sin. Through including this measure, I hope to understand exposure to heterosexism as a possible barrier as well. While homophobia is an antigay attitude, heterosexism provides the climate for this ideology, and thus participation in organizations with a heterosexist environment may expose gay men to homophobia. For this, I created four dummy variables: "Christianity," "Judaism," "other," and "not currently practicing any religion/ Atheism."

"Thinking about politics, which of the following best describes your political views" was included due to the understanding that, in the political sphere, an individual's views may not completely align with their identity. Here, conservatives typically support marriage between one man and one woman, yet there are multiple other issues related to conservative and liberal ideologies, such as the death penalty, economics, gun control, and healthcare. While an individual may agree with the ideology on multiple issues, they may disagree elsewhere, while still identifying with the ideology as it encompasses more of their ideologies. This is captured well in this variable, as it is measured on a six-point Likert scale: $1=$ "Very Liberal" and 6= "Very Conservative," with options for "very," "somewhat," and "liberal (or conservative)."

"Which of the following racial groups comes closest to identifying you?" was included as a means of addressing past literature regarding the policing of gay men of color's sexuality and the literature regarding the barriers gay men of color face within the LGBTQ+ community. While it is known that men of color are more likely to experience 
external homophobia (Chard et al. 2015), the focus of literature regarding gay men has primarily been centered on white gay men (Hill 2009, Hunter 2010, Ocampo 2014). Using this variable, I created four dummy variables: "Black," "Hispanic/ Latino," "other," and the reference group "White." Due to the small sample size of Native Americans $(n=28)$ and Asian/ Pacific Islander ( $\mathrm{n}=99)$, these were combined into the "other" category. Further, due to the unique experience of multiracial individuals and the different racial identities in which they may identify, these individuals were also included in the "other" category.

To understand the impact of physical location on outness among the gay men in this study, the respondents' geographical location was used in this analysis. Past studies have highlighted the religious and conservative ideologies that have dominated the Bible Belt located in the southern United States (Barton 2010). For this, I created four dummy variables: "Northeastern," "Midwest," "Western," and the reference group "Southern." Interaction Variables

For this study, I created three interaction variables to understand the interaction between race and homophobia is a problem in my communities. I created these three interaction variables to assess the impact of external homophobia on those with intersecting identities, particularly race and sexuality. As such, I created interaction variables for homophobia is a problem in my communities, specifically looking at how their response to this question impacted black gay men, Latino gay men, and other gay men of color.

Statistical Analysis

For this study, I used SPSS to perform an ordinary least square (OLS) regression. Several precautions were taken to ensure the validity of the results of this study. First, I 
used variance inflation factors to examine the independent variables for collinearity. By ensuring minimal collinearity between the independent variables, the models in this study more accurately identify what variables are and are not truly significant. To identify influential cases that required further investigation, I used Cook's distance statistic (Cook's D). Cook's D removes the case from the analysis and performs the regression to determine how much the regression changes without the case. For this study, I used the formula 4/ (n-k-1) as a threshold for determining influential cases. Cases with a Cook's D above the 0.0039 threshold were further investigated for removal. By examining cases with Cook's D above the given threshold, cases that influenced the data were removed from the study to maintain accuracy. I examined the residuals for normality using P-P plots and a histogram. P-P plots show randomness, which helps determine if there are missing variables that may increase this model's validity. I further used scatterplots to verify homoscedasticity of error variance. By ensuring homoscedasticity of the error variance, I ensured that the model did not have a bias in the responses. There is no one answer option in the independent variables that would bias the OLS regression models' line.

For this study, four models were created: demographics model, homophobia model, full model, and parsimonious model. In the demographics model, I examine the relationship between age, race, religion, political ideology, and region and level of outness among gay men. In the homophobia model, I assessed the relationship between homophobia is a problem in my communities, family rejection, and medical professional's comfort level and level of outness among gay men. In the full model, I assessed the relationship between the variables from both the demographics model and 
the homophobia model, as well as three interaction variables between race and homophobia is a problem in my community and the level of outness among gay men. Finally, a parsimonious model was created using backward selection ( $\mathrm{p}>.10$ to exit). The parsimonious model removes non-significant variables one at a time, ensuring that the right variables are included in the study. In the parsimonious model, I assessed the relationship between age, political ideology, race, Christianity, family rejection, medical professional's comfort level, homophobia is a problem in my communities, and the interaction variables for Black gay men and other gay men of color and level of outness among gay men. 


\section{CHAPTER 4: RESULTS}

This research project examines the relationship between external homophobia and the level of outness among gay men. To provide a more in-depth examination of outness among gay men, t-testing was performed, and the results are listed in Table 2 . The results of the OLS regression models are reported in Table 3.

The mean difference between racial groups' level of outness to family, friends, coworkers, neighborhood, online, and overall outness level is reported in Table 2. The results indicated that White gay men are more out to their family (.50), friends (.34), coworkers (.63), neighborhood (.51), and online (.57) compared to Black gay men. The results also indicated that White gay men are more out to their family (.46) than Latino gay men. Further, these results indicate that White gay men are more out to their family (.38) and neighborhood (.54) than other gay men of color. White gay men also reported higher levels of outness compared to Black gay men (2.55), Latino gay men (1.35), and other gay men of color (1.57).

The results of the four OLS models are reported in Table 3. The first model in this study tested demographic variables only. In the demographics model, a statisticallysignificant negative association was identified between political ideology (-.74) and outness. This model further indicates the impact of race on outness, with Black gay men (-2.14), Latino gay men (-1.12), and other gay men of color (-1.47) reporting lower levels 
of outness compared to White gay men. This model also shows a negative association between Christianity and outness, with those who were currently practicing Christianity (-.82) reporting a lower level of outness than those who were not currently practicing a religion. This model's adjusted R2 is .075, suggesting this model explains $7.5 \%$ of outness among gay men.

In the homophobia model, each of the variables entered were found to be statistically significant. The homophobia model found a statistically significant negative association between the level of agreement that homophobia is a problem in their community (-.22) and outness among gay men. That is, for each one-point increase in the level of agreement that homophobia is a problem in their community, there was a .22 decrease in the level of outness reported by gay men. This model also found a statistically significant negative association between rejection from family (-1.21) and outness among gay men. This indicates that for each one-point increase in feeling rejected by family, there was a 1.21 decrease in the level of outness reported by gay men. Further, a statistically significant positive relationship was found for both gay men who felt their medical professional was comfortable with the sexual orientation (2.66) and gay men who felt their medical professional was uncomfortable with their sexual orientation $(2.42)$ compared to gay men who were not out to their medical professional. This model's adjusted $\mathrm{R}^{2}$ is .221 , suggesting this model explains $22.1 \%$ of outness among gay men.

In the full model, several variables were statistically significant. The full model shows a statistically significant negative association between age (-.04) and outness among gay men, suggesting that for each one-year increase in age, there was a .04 decrease in the level of outness reported. This model also shows a negative association 
between political ideology (-.61) and outness among gay men, suggesting that gay men who identified as more conservative reported lower levels of outness. This model also shows a negative association between race and outness among gay men, with Black gay men (-4.73), Latino gay men (-2.78), and other gay men of color (-4.02) all reporting as less out compared to White gay men. This model further identified a negative association between Christianity (-.95) and outness among gay men, with gay men who identified as practicing Christianity reporting lower levels of outness than gay men who were not currently practicing a religion. A negative association was found between rejection from family $(-1.20)$ and outness among gay men, suggesting that gay men who report feeling less supported by their family reported decreased levels of outness. This model found a positive association between feeling that the respondent's medical professional was comfortable with the respondent's sexuality (2.78) and outness. This model further shows a positive association between feeling that the respondent's medical professional was uncomfortable or had ignored the respondent's sexuality (2.63) and outness. This model also found a statistically significant negative association between agreement that homophobia is a problem (-.54) and outness.

In the full model, an interaction variable was added to determine the impact of the level of agreement that homophobia is a problem when accounting for race. This was included to examine how the intersection of race and sexuality impacts the respondents' level of outness. Previous literature has shown that gay men of color face higher incidents of verbal and physical abuse in relation to their sexuality (Haas et al. 2011, McCune Jr. 2014, Ocampo 2012). For the full model, a statistically significant association between agreement that homophobia is a problem and outness for Black gay men (.56). For other 
gay men of color, the full model also finds a statistically significant association between agreement that homophobia is a problem and outness for other gay men of color (.62). The adjusted $\mathrm{R}^{2}$ for this model is .300 suggesting this model explains $30 \%$ of the variation in outness among gay men.

Finally, in the parsimonious model, the non-significant factors were removed, leaving only the statistically significant variables. The parsimonious model shows a negative association between age (-.04) and outness among gay men, suggesting that for each one-year increase in age, there was a .04 decrease in the level of outness reported. This model also shows a negative association between political ideology (-.62) and outness among gay men, suggesting that gay men who identified as more conservative reported lower levels of outness. This model also shows a negative association between race and outness among gay men, with Black gay men (-4.49), Latino gay men (-1.19), and other gay men of color (-3.65) all reporting as less out compared to White gay men. This model further identified a negative association between Christianity (-.90) and outness among gay men, with gay men who identified as practicing Christianity reporting lower levels of outness than gay men who were not currently practicing a religion. A negative association was found between rejection from family (-1.21) and outness among gay men, suggesting that gay men who report feeling less supported by their family reported decreased levels of outness. This model found a positive association between feeling that the respondent's medical professional was comfortable with the respondent's sexuality (2.73) and outness. This model further shows a positive association between feeling that the respondent's medical professional was uncomfortable or had ignored the 
respondent's sexuality (2.65) and outness. This model also found a negative association between agreement that homophobia is a problem (-.43) and outness.

In the parsimonious model, the interaction variables for Black gay men and other gay men of color remained in the model. The interaction variable for Latino gay men was not significant and was not included in the parsimonious model. The parsimonious model finds a statistically significant association between agreement that homophobia is a problem and outness for Black gay men (.48). For other gay men of color, the parsimonious model finds a statistically significant negative association between agreement that homophobia is a problem (.53) and outness. This model's adjusted $\mathrm{R}^{2}$ is .301 , suggesting this model explains $30.1 \%$ of the variation in outness among gay men.

A few factors in this study were not statistically significant in any model. In terms of religion, involvement in Judaism or other religions did not produce a statistically significant difference in the level of outness among gay men in any of the models. Further, each model found no statistically significant difference in the level of outness for gay men living in the Northeastern, Midwestern, or Western United States compared to gay men living in the Southern United States. 


\section{CHAPTER 5: DISCUSSION}

For gay men, the process of coming out to others is often a very difficult decision. Throughout society, the social construction of sexuality has presented heteronormative sexuality as normal while devaluing same-sex relationships (Seidman 2010). This heteronormative construction has created an environment where gay men are defined as different and thus punished through their placement in the stratified social hierarchy. Gay men's devalued position in the stratified social hierarchy comes with threats to gay men in the form of verbal and physical violence (Bhana and Mayeza 2016, Franklin 1998, McCune Jr. 2014). As such, gay men often must choose between feeling as if they live a lie or the repercussions of coming out if their coming out is deemed explosive knowledge (Orne 2011).

Prior studies have focused on the process of coming out among gay men. However, these studies have often presented White, middle-class gay men's experience as the experience of all gay men, thus marginalizing the experience of gay men of color (Hill 2009, Hunter 2010, Ocampo 2014). These studies have also often focused on the psychological aspects of coming out (Orne 2011). By focusing on the psychological aspects of coming out, past researchers have missed discussing the relations between gay men and society. Thus, the purpose of this quantitative study was to examine how external homophobia affects gay men's level of outness. Using the Social Justice Sexuality Survey data, this study examined how much did was the impact of external 
homophobia on the level of outness among gay men. This study found three main conclusions. First, this study's results support the hypothesis that as gay men are exposed to more external homophobia, their level of outness will decrease. Second, this study's results suggest that exposure to external homophobia disproportionately impacts Black, Latino, and other gay men of color. Third, this study's results suggest an overlap in the hierarchy of masculinity that has not previously been discussed.

External Homophobia and Outness

In this study, lower levels of outness were reported by gay men who were involved in institutions that have constructed and reified heteronormative constructs of sexuality. That is, statistically significant negative relationships were found between involvement in Christianity and more conservative politics. Historically, Christianity has praised heterosexual relationships as morally superior while devaluing gay identities (Seidman 2010). Through the normalization of heterosexuality, Christianity has created a moral opposition to other non-heterosexual sexualities. To do this, Christianity has used its broad reach into other social institutions to legitimize this construction of sexuality. One considerably powerful tie of Christianity is the ties to politics. Through Christianity's ties to politics, queer movements have often faced staunch opposition to policies that would address inequality faced by the queer community (Seidman 2010). This opposition has typically come from those who are socially conservative. The Republican Party, which is typically associated with conservative ideologies, has as part of their national party platform references to "the American family" and notes that "the cornerstone of the family is natural marriage, the union of one man and one woman" (Republican National Committee 2020). The Republican Party platform makes clear the relationship with Christianity through their "support [of] the public display of the Ten Commandments" 
(Republican National Committee 2020). Thus, given the history of constructing heteronormative sexuality in Christianity and conservativism, along with the reification through acts of external homophobia such as exclusion, the finding that gay men who identified with these ideologies were less out was expected.

This study further found that gay men who agreed that homophobia is a problem in their community reported decreased levels of outness. That is, a statistically significant negative relationship was found between agreement that homophobia is a problem in one's community and level of outness. Past research has found that gay men coming out may use different methods of coming out depending on if their coming out will be deemed explosive knowledge. That is, gay men must determine if their coming out will be a danger to themselves or others around them (Orne 2011). However, for gay men, many instances show the dangers of failing to conform to heteronormative expectations (Franklin 1998, Herek 2004). These heteronormative expectations are often reinforced through bullying and verbal/ physical assault (Franklin 1998, Herek 2004, McCune Jr. 2014) and many stories serve as reminders of the possibilities faced when coming out. However, past studies have shown that these acts of bullying and verbal and physical assault are not merely hatred or repressed homosexuality, as some would suggest, but are instead methods of reinforcing hierarchical gender norms (Franklin 1998). Thus, given the threat of external homophobia via bullying, physical and verbal assault, the finding that gay men who felt that homophobia was a problem were less out was expected.

This study also found that gay men who felt more rejection from their family reported decreased levels of outness. For many gay men, coming out to family is an important milestone, yet poses severe risks. In the process of coming out to family, gay 
men often weigh the benefits of coming out against the possibility that their coming out is explosive knowledge (Orne 2011). If their coming out is explosive knowledge, gay men risk severe outcomes, including loss of support networks (Ocampo 2014, Orne 2011, Haas et al. 2011). Thus, given the risk of losing support networks, the finding that as gay felt more rejected by their family their level of outness decreases was expected.

Race and Outness

This study shows that Black gay men and other gay men of color were disproportionately impacted by homophobia in their communities. This composite variable accounts for both the respondent's racial and ethnic community and the respondent's neighborhood. The finding suggests that Black gay men and other gay men of color were particularly more motivated to remain closeted than white gay men, which aligns with past research regarding race and sexuality. Studies have shown that Black gay men experience policing of their performance of masculinity and their adherence to heteronormative expectations. This policing is often in the form of assault and rejection (Herek 2004, McCune Jr. 2014). Further, Black gay men and other gay men of color deciding if they should come out may identify this information as explosive knowledge, as they often face racism in the gay community and risk losing support from their social networks (Ocampo 2012, Orne 2011).

This study shows that White gay men were consistently more out compared to Black gay men. This finding aligns with past research regarding the intersection of race and sexuality. Black gay men face constant policing of their performance of masculinity and adherence to heteronormative expectations. This policing is done through physical and verbal assault, and the constant media focus on Black men's sexuality (McCune Jr. 
2014). Through this focus from the media, the private matters of Black gay men have been used "as fodder for public consumption and obsession" (McCune Jr. 2014).

Dating back to the 1970s, mainstream media has often portrayed gay men as a threat to American ideals, someone who was a danger to children, families, morals, and national security (Seidman 2010). However, in the 1990s, the media began to shift towards a positive, more tolerant image of gay men, though these images were only ones that would not bother heteronormative ideology (Seidman 2010). As such, gay men's image has been understood as white and effeminate (McCune Jr. 2014). However, media representations for Black gay men have not been the same. Media has provided very little representation of Black gay men in shows and movies (McBride 2005). When Black gay men are represented in media, they are often represented as "on the down-low." That is, the term down-low is often used to describe "problematic Black men who sleep with other men while having relationships with wives/ girlfriends" (McCune Jr. 2014). The media has increasingly focused on this aspect of Black gay men, using the private matters of the gay black man "as fodder for public consumption and obsession" (McCune Jr. 2014). Yet, this down-low space has historically existed outside the realm of sexuality and, as such, points to the sociocultural factors the necessitate such a space. That is, the down-low allows for Black gay men to regain agency in light of the constant surveillance from media and others who police their gender performance and sexuality. However, in doing so in down-low spaces, Black gay men can "celebrate the ideals of black masculinity while acting on queer desires" (McCune Jr. 2014). Given that prior studies have shown clear instances of the levels of external homophobia Black gay men face via physical and verbal assault as ways of maintaining norms regarding masculinity and 
sexuality (Bhana and Mayeza 2016, Chard et al. 2015, McCune Jr. 2014), the finding that Black gay men were less out than White gay men was expected.

In this study, White gay men were found to be more out compared to Latino gay men. This finding is also aligned with past research. In a study of Latino gay immigrants, gay men discussed the "hyperbolized displays of femininity," which "further crystallized patriarchal, homophobic attitudes that remain prominent in ... Latin America" (Ocampo 2014). Thus, Latino gay men also pointed to how media constructed sexuality and how it reified the constructs that disadvantaged these gay men. These Latino gay men were motivated to remain closeted in many instances due to their family's response to the media's portrayal of gay characters and the rejection of parents/ caregivers (Haas et al. 2011, Ocampo 2014). However, it was not only the familial relations that motivated Latino gay men to remain closeted. That is, Latino gay men may fear "losing socioeconomic or social support from family and co-ethnic networks" (Ocampo 2014). While White gay men can typically find support if they face a loss of these networks, gay men of color often face issues of racism within the queer community, and therefore the risks often do not outweigh the benefits of coming out (Ocampo 2014, Orne 2011). Thus, while media constructs and reifies sexuality in a way that disadvantages Latino gay men, heteronormative expectations are often reinforced through familial relationships. Given the risk of losing support, the understanding that coming out may be explosive knowledge and racism in the queer community continues to serve as a barrier for Latino gay men, the finding that Latino gay men are less out than White gay men was expected. Among the previously mentioned work with which these results align, gay men of color further face issues of racism within the queer community (Hunter 2010, Orne 
2011). These issues of racism lead to gay men of color finding less support in the queer community, and thus they remain closeted or use other methods to navigate their sexuality so that they do not risk the loss of support networks (Ocampo 2014, Orne 2011). As queer people of color have worked to address the lack of intersectionality within the queer community, they are often met with resistance (Arana 2017). Many in the queer community have opposed intersectional approaches to addressing issues within the queer community. These individuals have argued that intersectional approaches divide the queer community's power and that issues that affect all queer individuals are being addressed. This again returns to the construction of sexuality. During the 1990s, when the media was attempting to create palatable images of what gay men were like, the more positive image of gay men was created in a way that did not bother heteronormative ideals (Seidman 2010). In doing so, media created a typification of gay men which was white and effeminate (McCune Jr. 2014), which has otherized those who do not fit this typification. As such, the issues of White gay men are legitimized while the issues of gay men of color are marginalized. Thus, the finding that gay men of color are less out than White gay men is not unexpected and aligns with the hypothesis that gay men who experience more external homophobia are less out.

This study also shows that Black gay men and other gay men of color were more out as their level of agreement that homophobia is a problem in their racial community/ ethnic community/ neighborhood increased. Previous studies have shown that Black gay men are policed for their gender performance and sexuality (McCune Jr. 2014). The finding that Black gay men who increasingly identified homophobia as a problem was more out than those who did not may be related to previous literature on how Black gay 
men navigate their sexuality. That is, given the increased policing of Black gay men's sexuality, Black gay men may utilize down-low spaces to "celebrate the ideals of Black masculinity while acting on queer desires" (McCune Jr. 2014). However, those who utilize down-low spaces also require dramaturgical loyalty. According to Goffman, actors choose other people they can ensure will not betray the performer's secret for any reason (Goffman 1959). This aspect is essential, particularly for gay men of color, as they risk "losing socio-economic or social support from family and co-ethnic networks" (Ocampo 2014). Therefore, it is possible that, as Black gay men and other gay men of color experience more homophobia from their racial community/ ethnic community/ neighborhood, they utilize down-low spaces to maintain their heterosexual identity while acting on queer desires. However, as they utilize the down-low spaces, Black gay men and other gay men of color also grow their network of individuals who know their sexuality.

Intersectionality and Hierarchy of Masculinity

In Connell's discussion of the hierarchy of masculinity, Connell explains that men who do not meet hegemonic masculinity goals are positioned in the stratified social hierarchy below those who do meet hegemonic masculinity's goals and thus receive fewer resources (Connell and Messerschmidt 2005, Connell 1995). Of particular interest in this study was marginalized masculinities and subordinated masculinities. Connell uses the term marginalized masculinities to refer to men who cannot meet society's definition of hegemonic masculinity due to their race or class. Connell notes in this discussion that men of color may indeed be considered exemplars of hegemonic masculinity, the social authority of men of color is not affected by the few who can achieve such status (Jefferson 2002). In further discussing the relations of masculinity, Connell discusses that 
men whose masculinity is easily related to femininity are considered subordinate. Notably, this is applied to gay men, as stereotypes related to taste in home dècor and fashion, the belief that gay men are weak, and the act of same-sex intercourse lead to stereotypes that gay men are feminine (Bhana and Mayeza 2016, Connell 1995, Donaldson 1993). However, Connell's discussion of masculinities does not capture the intricacies of how men who are oppressed in intersecting identities are positioned in the stratified social hierarchy.

In this study, Black gay men, Latino gay men, and other gay men of color reported decreased levels of outness compared to White gay men. This study further found that as Black gay men and other gay men of color's level of agreement that homophobia is a problem in their racial community/ ethnic community/ neighborhood increased, their level of outness did as well. Prior studies on race and sexuality have found that Black gay men experience physical and verbal violence as a means of enforcing norms of Black masculinity (McCune Jr. 2014). Other gay men of color also face rejection related to their sexuality from their social network and co-ethnic networks (Ocampo 2012, Orne 2011). As a means of maintaining their straight identity while also acting on queer desires, Black gay men may utilize down-low spaces (McCune Jr. 2014). By doing so, this helps Black gay men to mitigate the risks of losing support from their family and co-ethnic networks. However, studies have also shown that gay men of color face issues within the queer community. In the queer community, gay men of color also face racism and receive less support than White gay men when attempting to overcome barriers (Ocampo 2012). As media has tried to create a palatable image of gay men, the representation created has been primarily white (Seidman 2010). As such, the idealized 
gay man has also become white, thus making gay men of color appear as an anomaly in the gay community. Therefore, gay men of color do not meet the definition of hegemonic masculinity yet find less access to resources among marginalized masculinities (race) and subordinated masculinities (sexuality).

According to Connell's discussion of masculinity, men are expected to position themselves according to hegemonic masculinity. However, gay men of color are not only placed according to hegemonic masculinity but also according to other forms of masculinity. Connell discusses that men of color are considered marginalized in relation to hegemonic masculinity. However, Black gay men face external homophobia as a means of policing their adherence to Black masculinity, not hegemonic masculinity, which is centered in whiteness. Connell also discusses that gay men are considered subordinated in relation to hegemonic masculinity. However, gay men of color face racism among the queer community for not meeting the idealized gay male image, which again is centered in whiteness. Thus, gay men of color are not positioned according to hegemonic masculinity's definition, but instead, according to a subordinated masculinity.

By examining the level of outness of gay men of color in relation to previous studies, this study suggests that men are not only placed in the stratified social hierarchy according to their relation to hegemonic masculinity but to other masculinities as well. That is, Black gay men, Latino gay men, and other gay men of color risk losing access to resources in a way that is not encompassed by merely discussing their masculinity as marginalized or subordinated. Among men who are marginalized in our current understanding of the hierarchy of masculinity, gay men of color are subordinated due to the heteronormative expectations. Thus, gay men of color risk losing resources when 
coming out to their co-ethnic networks (Ocampo 2014). However, among men who are subordinated, gay men of color are marginalized due to their race. As such, gay men of color are unsupported in the queer community, and their needs are often not represented in addressing the queer community's needs (Ocampo 2014, Orne 2011). As such, the finding that Black gay men, Latino gay men, and other gay men of color are less out suggests that, when choosing to come out or remain closeted, these men must understand their position in the stratified hierarchy according to not only hegemonic masculinity, but other forms of masculinity as well.

\section{Limitations}

Although this research project gives insight into the barrier of external homophobia in coming out for gay men, there were limitations to this project. The first limitation is the lack of qualitative data to bolster these findings. While this research project shows that involvement in these settings decreases gay men's level of outness, more information regarding the experiences in these settings would be useful in determining appropriate actions for organizations to take address inequality. Another limitation of this data is the method used to collect the data. This data was collected through multiple strategies, each of which would lead to higher samples of gay men who are more out. The strategies used to collect this data were "venue-based sampling at strategic events, snowball sampling, respondent-driven sampling, and the internet" (Battle 2010). However, gay men who are not out to others are most likely not going to be at events, may be unknown to other gay men, and may be unwilling to answer questions about their sexuality on the internet. Therefore, this research is limited as it may not capture those who are completely closeted. 
Recommendations for Future Research

Based on this study, there are recommendations for future researchers. This study found that homophobia in my communities disproportionately impacted Black gay men and other gay men of color. This highlights the need for studies addressing intersectionality in queer studies, as past studies have often failed to encompass this interaction and, as such, much of the existing literature presents the experience of White gay men as those of the queer community as a whole. Thus, while this research was focused on gay, cisgender men's experiences, future research should focus on more intersecting identities. While research has shown that gay men of color are excluded from the queer community, research has also highlighted this concern for Black lesbian women (Ocampo 2014). Therefore, addressing the experiences of external homophobia among other intersecting identities such as lesbian women of color can help to highlight the difference in experiences in coming out for those with different intersecting identities. Future research focusing on different intersections can help address how sexuality is constructed and how these constructions disadvantage gay men of color. Another recommendation for future research would be to include qualitative data as well. While this may not be easy given the topic, the addition of qualitative data to the findings can highlight what methods of external homophobia are seen in different settings. By doing so, more direct information regarding how these institutions reify heteronormative expectations of sexuality can be collected, thus giving more insight into the impact of external homophobia on the level of outness. 


\section{REFERENCES}

Aksoy, Cevat Giray, Christopher S. Carpenter, Jefferson Frank and Matt L. Huffman. 2018. "Gay Glass Ceilings: Sexual Orientation and Workplace Authority in The." (https://voxeu.org/article/gay-glass-ceilings-sexual-orientation-and-workplaceauthority-uk).

Banks, Christopher. 2003. "The Cost of Homophobia: literature Review on The human Impact Of homophobia In canada."

Battle, Juan. 2010, "Social Justice Sexuality".

Bhana, Deevia and Emmanuel Mayeza. 2016. "We Don't Play with Gays, They're Not Real Boys ... They Can't Fight: Hegemonic Masculinity and (Homophobic) Violence in the Primary Years of Schooling." Volume 51:36-42. (http://dx.doi.org/10.1016/j.ijedudev.2016.08.002).

Chard, Anna N., Catherine Finneran, Patrick S. Sullivan and Rob Stephenson. 2015. "Experiences of Homophobia among Gay and Bisexual Men: Results from a Cross-Sectional Study in Seven Countries." Culture, Health, \& Sexuality 17(10):1174-89.

Connell, R W and James W. Messerschmidt. 2005. "Hegemonic Masculinity: Rethinking the Concept." Gender \& Society 19(6):829-59.

Connell, R.W. 1995. Masculinities. Berkeley and Los Angeles, CA: University of California Press.

Connell, R.W. 2005. Masculinities. Berkeley and Los Angeles, California: University of California Press.

Diamond, Milton. 2002. "Sex and Gender Are Different: Sexual Identity and Gender Identity Are Different." Clinical Child Psychology \& Psychiatry 7(3):320-34.

Donaldson, Mike. 1993. "What Is Hegemonic Masculinity?". 22(5):643-57.

Franklin, Karen. 1998. "Inside the Mind of People Who Hate Gays." Pp. 1-20 in Unassuming Motivations: Contextualizing the Narratives of Antigay Assailants, edited by H. G. M. Thousand Oaks, CA: Sage Publications.

Goffman, Erving. 1959. The Presentation of Self in Everyday Life: Anchor Books.

Haas, Ann P., Mickey Eliason, Vickie M. Mays, Robin M. Mathy, Susan D. Cochran, Anthony R. D'Augelli, Morton M. Silverman, Prudence W. Fisher, Tonda Hughes, Margaret Rosario, Stephen T. Russell, Effie Malley, Jerry Reed, David A. Litts, Ellen Haller, Randall L. Sell, Gary Remafedi, Judith Bradford, Annette L. Beautrais, Gregory K. Brown, Gary M. Diamond, Mark S. Friedman, Robert Garofalo, Mason S. Turner, Amber Hollibaugh and Paula J. Clayton. 2011. "Suicide and Suicide Risk in Lesbian, Gay, Bisexual, and Transgender Populations: Review and Recommendations." Journal of Homosexuality 58(1):10-51. doi: 10.1080/00918369.2011.534038.

Herek, Gregory M. 2004. "'Beyond Homophobia": Thinking About Sexual Prejudice and Stigma in the Twenty-First Century." Sexuality Research and Social Policy 1(2). 
Hill, Natalie L. 2009. "Affirmative Practice and Alternative Sexual Orientations: Helping Clients Navigate the Coming out Process." Clinical Social Work Journal 37(4):346-56. doi: 10.1007/s10615-009-0240-2.

Houghton, Angela. 2018. "Maintaining Dignity: A Survey of Lgbt Adults Age 45 and Older." AARP Research.

Human Rights Campaign. 2019, "Glossary of Terms". Retrieved January 29, 2019, 2019 (https://www.hrc.org/resources/glossary-of-terms).

Hunter, M. A. 2010. "All the Gays Are White and All the Blacks Are Straight: Black Gay Men, Identity, and Community." Sexuality Research and Social Policy 7(2):8192. doi: 10.1007/s13178-010-0011-4.

Jefferson, Tony. 2002. "Subordinating Hegemonic Masculinity." Theoretical Criminology 6(1):63-88.

Juan Battle, Antonio, Jay Pastrana Jr and Jessie Daniels. 2013. "Social Justice Sexuality Project: 2010 National Survey, Including Puerto Rico."

Kite, ME and BE Jr Whitley. 1998. "Do Heterosexual Women and Men Differ in Their Attitudes toward Homosexuality? A Conceptual and Methodological Analysis." in Stigma and Sexual Orientation: Understanding Prejudice against Lesbians, Gay Men, and Bisexuals, edited by G. M. Herek: Sage Publications.

Klitzman, Robert L. and Jason D. Greenberg. 2002. "Patterns of Communication between Gay and Lesbian Patients and Their Health Care Providers." Journal of Homosexuality 42(4):65-75.

Ocampo, Anthony C. 2014. "The Gay Second Generation: Sexual Identity and Family Relations of Filipino and Latino Gay Men." Journal of Ethnic and Migration Studies 40(1):155-73.

Orne, Jason. 2011. "'You Will Always Have To "Out" Yourself': Reconsidering Coming out through Strategic Outness." Sexualities 14(6):681-703.

Page, Amy Dellinger and James R. Peacock. 2013. "Negotiating Identities in a Heteronormative Context." Journal of Homosexuality 60(4):639-54.

Pew Research Center. 2017, "Changing Attitudes on Gay Marriage": Pew Research Center. 2019.

Ritzer, George and Jeffrey Stepnisky. 2018. "Classical Sociological Theory." Los Angeles: Sage. Retrieved.

West, Candace and Don H. Zimmerman. 1987. "Doing Gender." 1(2):125-51.

West, Candace and Sarah Fenstermaker. 1995. "Doing Difference." Gender and Society $9(1): 8-37$. 
Table 1. Descriptive Statistics for Gay Men in Social Justice Sexuality Survey (N=987)

\begin{tabular}{|c|c|c|}
\hline Variable & Mean & Range \\
\hline \multicolumn{3}{|l|}{ Dependent Variable } \\
\hline Outness & 14.83 & $\begin{array}{l}0 \text { Out to none } \\
20 \text { Out to all }\end{array}$ \\
\hline \multicolumn{3}{|l|}{ Demographic Variables } \\
\hline Age & 36.72 & $\begin{array}{l}13 \text { years old } \\
81 \text { years old }\end{array}$ \\
\hline Political Ideology & 2.18 & $\begin{array}{l}1 \text { Very liberal } \\
6 \text { Very conservative }\end{array}$ \\
\hline \multicolumn{3}{|l|}{ Race } \\
\hline $\begin{array}{r}\text { Black } \\
\text { Latino } \\
\text { Other } \\
\text { White }\end{array}$ & $\begin{array}{l}34.35 \% \\
19.45 \% \\
20.06 \% \\
26.14 \%\end{array}$ & \\
\hline $\begin{array}{l}\text { Region } \\
\qquad \begin{array}{c}\text { Northeast } \\
\text { Midwest } \\
\text { West } \\
\text { South }\end{array}\end{array}$ & $\begin{array}{l}26.24 \% \\
15.40 \% \\
31.71 \% \\
26.65 \%\end{array}$ & \\
\hline $\begin{array}{c}\text { Religion } \\
\text { Christianity } \\
\text { Judaism } \\
\text { Other } \\
\text { No Religious Affiliation }\end{array}$ & $\begin{array}{l}39.51 \% \\
6.38 \% \\
23.91 \% \\
30.19 \%\end{array}$ & \\
\hline \multicolumn{3}{|l|}{ Independent Variables } \\
\hline Family Rejection & 2.47 & $\begin{array}{l}1 \text { Completely supported } \\
6 \text { Not supported at all }\end{array}$ \\
\hline $\begin{array}{l}\text { Medical Professional } \\
\text { Comfortable } \\
\text { Uncomfortable/ Ignored } \\
\text { Did not know }\end{array}$ & $\begin{array}{l}68.49 \% \\
11.25 \% \\
20.26 \%\end{array}$ & \\
\hline Homophobia & & $\begin{array}{l}1 \text { Strongly disagree } \\
6 \text { Strongly agree }\end{array}$ \\
\hline $\begin{array}{l}\text { Homophobia is a problem } \\
\text { Homophobia is a problem } * \text { Black } \\
\text { Homophobia is a problem } * \text { Latino } \\
\text { Homophobia is a problem } * \text { Other }\end{array}$ & $\begin{array}{l}4.05 \\
1.71 \\
0.91 \\
0.92\end{array}$ & \\
\hline
\end{tabular}


Table 2. Mean Difference between Racial Groups Level of Outness to Different Communities in Social Justice Sexuality Survey

\begin{tabular}{|c|c|c|c|c|}
\hline & Black & $\begin{array}{c}\text { Latino/ } \\
\text { Hispanic }\end{array}$ & Other & White \\
\hline \multicolumn{5}{|l|}{ Family } \\
\hline \multicolumn{5}{|l|}{ Black } \\
\hline Latino/ & .04 & & & \\
\hline \multicolumn{5}{|l|}{ Hispanic } \\
\hline Other & .12 & .07 & & \\
\hline White & $.50 * * *$ & $.46 * * *$ & $.38 * *$ & \\
\hline \multicolumn{5}{|l|}{ Friends } \\
\hline \multicolumn{5}{|l|}{ Black } \\
\hline Latino/ & .14 & & & \\
\hline \multicolumn{5}{|l|}{ Hispanic } \\
\hline Other & .15 & .01 & & \\
\hline White & $.34 * * *$ & .20 & .19 & \\
\hline \multicolumn{5}{|l|}{ Coworker } \\
\hline \multicolumn{5}{|l|}{ Black } \\
\hline Latino/ & $.40 *$ & & & \\
\hline \multicolumn{5}{|l|}{ Hispanic } \\
\hline Other & -.30 & -.10 & & \\
\hline White & $.63 * * *$ & .23 & .33 & \\
\hline \multicolumn{5}{|l|}{ Neighborhood } \\
\hline \multicolumn{5}{|l|}{ Black } \\
\hline Latino/ & -.21 & & & \\
\hline \multicolumn{5}{|l|}{ Hispanic } \\
\hline Other & -.03 & -.24 & & \\
\hline White & $.51 * *$ & .31 & $.54 * * *$ & \\
\hline \multicolumn{5}{|l|}{ Online } \\
\hline \multicolumn{5}{|l|}{ Black } \\
\hline Latino/ & $.41 * * *$ & & & \\
\hline \multicolumn{5}{|l|}{ Hispanic } \\
\hline Other & $.44 * * *$ & .03 & & \\
\hline White & $.57 * * *$ & .16 & .13 & \\
\hline \multicolumn{5}{|l|}{ Outness } \\
\hline \multicolumn{5}{|l|}{ Black } \\
\hline Latino/ & $1.20 *$ & & & \\
\hline \multicolumn{5}{|l|}{ Hispanic } \\
\hline Other & .98 & -.23 & & \\
\hline White & $2.55 * * *$ & $1.35 *$ & $1.57 * *$ & \\
\hline
\end{tabular}


Table 3. Ordinary least squares regression models predicting outness of gay men from the Social Justice Sexuality Survey $(\mathrm{N}=987)$

\begin{tabular}{|c|c|c|c|c|}
\hline Variable & $\begin{array}{l}\text { Demographic } \\
\text { Model }^{1}\end{array}$ & $\begin{array}{l}\text { Homophobia } \\
\text { Model }^{2}\end{array}$ & $\begin{array}{l}\text { Full } \\
\text { Model }^{3}\end{array}$ & $\begin{array}{l}\text { Parsimonious } \\
\text { Model }^{4}\end{array}$ \\
\hline Constant & $18.13 * * *$ & $16.61 * * *$ & $21.88 * * *$ & $21.59 * * *$ \\
\hline Age & -.007 & --- & $-.04 *$ & $-.04 * *$ \\
\hline Political Ideology & $-.74 * * *$ & --- & $-.61 * *$ & $-.62 * * *$ \\
\hline \multicolumn{5}{|l|}{ Race } \\
\hline Black & $-2.14 * * *$ & --- & $-4.73 * * *$ & $-4.49 * * *$ \\
\hline Latino & $-1.12 *$ & --- & $-2.78 *$ & $-1.19 * *$ \\
\hline Other Race & $-1.47 *$ & --- & $-4.02 * * *$ & $-3.65 * * *$ \\
\hline \multicolumn{5}{|l|}{ Region } \\
\hline Northeast & .342 & --- & -.03 & --- \\
\hline Midwest & -.012 & --- & -.04 & --- \\
\hline West & .378 & --- & .31 & --- \\
\hline \multicolumn{5}{|l|}{ Religion } \\
\hline Christianity & $-.82 *$ & --- & $-.95 * *$ & $-.90 * * *$ \\
\hline Judaism & -.07 & --- & .08 & --- \\
\hline Other Religion & -.24 & --- & -.18 & --- \\
\hline $\begin{array}{l}\text { Family Rejection } \\
\text { Medical } \\
\text { Professional }\end{array}$ & --- & $-1.21 * * *$ & $-1.20 * * *$ & $-1.21 * * *$ \\
\hline Comfortable & --- & $2.66 * * *$ & $2.78 * * *$ & $2.73 * * *$ \\
\hline $\begin{array}{l}\text { Uncomfortable/ } \\
\text { Ignored } \\
\text { Homophobia }\end{array}$ & --- & $2.42 * * *$ & $2.63 * * *$ & $2.65 * * *$ \\
\hline $\begin{array}{l}\text { Homophobia is a } \\
\text { problem }\end{array}$ & --- & $-.22 * * *$ & $-.54 * * *$ & $-.43 * * *$ \\
\hline $\begin{array}{l}\text { Homophobia is a } \\
\text { problem * Black }\end{array}$ & --- & --- & $.56 * *$ & $.48 * *$ \\
\hline $\begin{array}{l}\text { Homophobia is a } \\
\text { problem * Latino }\end{array}$ & --- & --- & .36 & --- \\
\hline $\begin{array}{l}\text { Homophobia is a } \\
\text { problem * Other }\end{array}$ & --- & --- & $.62 * *$ & $.53^{*}$ \\
\hline $\begin{array}{l}\text { 1. Adjusted R } \\
\text { 2. Adjusted R } \\
\text { 3. Adjusted R } \\
\text { 4. Adjusted R } \\
* * * \mathrm{p}<.001\end{array}$ & $\begin{array}{l}075 \\
241 \\
300 \\
301 \\
<.01\end{array}$ & & & \\
\hline
\end{tabular}




\title{
CURRICULUM VITA
}

\author{
NAME: $\quad$ Thomas Charles Isaak Jr \\ Address: 1416 Parkland Trail \\ Jeffersonville, IN 47130 \\ DOB: $\quad$ Covington, $\mathrm{TN}-$ April 27, 1991
}

\section{EDUCATION:}

B.S., Sociology

Murray State University

December 2013

M.A., Sociology

University of Louisville

December 2020

Ph.D., Sociology

University of Louisville

Accepted, begin in January 2021

\section{PROFESSIONAL SOCIETIES:}

Alpha Kappa Delta

American Sociological Association 